\title{
Age-of-acquisition effects in native speakers and second-language learners
}

\author{
EGBERT M. H. ASSINK, SONJA VAN WELL, and PAUL P. N. A. KNUIJT \\ Utrecht University, Utrecht, The Netherlands
}

\begin{abstract}
Two lexical decision experiments were conducted to study the locus of age-of-acquisition (AoA) effects in skilled readers with English or Dutch as their first language. AoA effects have generally been explained in terms of phonological processing. In Experiment 1, Dutch elementary school and secondary school students were presented with words factorially manipulated on surface frequency and AoA). Two main effects and an interaction were found, confirming findings reported for English speakers by Gerhand and Barry (1999). In addition, a language development effect was established: AoA effects decreased with reading age. Elementary school students showed the largest AoA effects. Experiment 2 used two groups of subjects. The first group consisted of Dutch students enrolled in a master's degree program in English. The second group consisted of native speakers of English. All subjects were presented with the experimental set of words used by Gerhand and Barry (1999). British subjects showed the same response pattern as reported by Gerhand and Barry (1999). The question of interest was whether Dutch subjects would show an AoA effect on the English set or not. The answer was affirmative. Dutch subjects produced identical response patterns as the British group, showing only an overall 94-msec latency delay. This result challenges predictions of the phonological completeness hypothesis. Alternative accounts in terms of semantic processing are discussed.
\end{abstract}

The question of how early- and late-acquired words are accessed in the mental lexicon has recently received considerable attention (e.g., Ellis \& Morrison, 1998; Gerhand \& Barry, 1998, 1999; Morrison \& Ellis, 1995; Morrison, Ellis, \& Quinlan, 1992; Turner, Valentine, \& Ellis, 1998). In many studies, effects of age of acquisition (AoA) are studied in combination with surface word frequency. Effects of AoA have been reported in picture naming (e.g., Barry, Morrison, \& Ellis, 1997), wordnaming latencies (Gerhand \& Barry, 1998; Morrison \& Ellis, 1995), and lexical decision latencies (e.g., Turner et al., 1998). In this study, we focus on the question of whether there are joint effects of word frequency and AoA in the lexical decision task (LDT).

Many studies have shown an effect of word frequency in LDT, but the results for AoA are less consistent, possibly because different sets of words in different experiments are not always matched on the same criteria. Earlier studies failed to match words on critical variables such as concreteness or imageability. Researchers have tried to solve this problem by using multiple regression techniques (e.g., Gilhooly \& Logie, 1982) or semifacto-

Parts of the research reported in this paper were presented at the 2001 meeting of Society for the Scientific Study of Reading. We thank staff and pupils of De Wilge elementary school in Hilversum and students of the Bonifacius secondary school and Utrecht University. We also thank Milou Beasley, Eline Megens, and Anne Waalkens for collecting the data for Experiment 2. Correspondence should be addressed to E. M. H. Assink, De Ridderlaan 43, 3417 CE Montfoort, The Netherlands (e-mail: e.assink@myrealbox.com). rial designs (e.g., Morrison \& Ellis, 1995). Recent studies have featured a fully factorial design with word materials matched on critical variables such as word length, syllable structure, and concreteness (e.g., Gerhand \& Barry, 1998). The emerging picture from experiments using these improved orthogonal stimulus sets is that AoA effects are demonstrably reliable, complementary to the well-established word frequency effects. Zevin and Seidenberg (2002), however, still question this point.

An important theoretical issue concerns the stage at which AoA and word frequency exert their influence. Theoretical models of word recognition such as Morton's (1969) logogen model and Seidenberg and McClelland's (1989) interactive activation model suggest that word frequency and AoA might well work at different stages in processing. Lexical decisions to high-frequency words are made on the basis of visual familiarity, whereas lowfrequency words require extra time through timeconsuming lexical checking. Gerhand and Barry (1998) have posited that AoA exerts its influence at a stage of processing following the initial visual familiarity check. This assumption is based on the general finding (Gilhooly \& Watson, 1981) that AoA effects are most robust in tasks that involve overt naming.

Evidence for the involvement of phonology in AoA effects in lexical decision was presented by Gerhand and Barry (1999). In a series of five LDT experiments, these authors investigated the effect of interfering phonological manipulations during task performance. The first experiment featured a conventional LDT using a fully factorial design manipulating AoA and word frequency, con- 
trolling for concreteness, imageability, and word length. Experiments 2-5 involved various attempts to interfere with reliance on phonology. Interference manipulations varied, including pseudohomophone nonwords (Experiment 2) and a recited nursery rhyme (Experiment 5). The AoA effect was reduced in the interference conditions, but it was not eliminated. Gerhand and Barry (1999) proposed that AoA has its primary effect on the retrieval of lexical phonology, which appears to be consulted automatically during the LDT (Gerhand \& Barry, 1999).

The question is why the AoA effect did not completely disappear in the Gerhand and Barry (1999) experiments. In the present experiments, we use a reading model that automatically involves some form of phonological processing (e.g., Lukatela \& Turvey, 1994a, 1994b; Van Orden, 1987; Van Orden \& Goldinger, 1994). In these phonological mediation models, on initial encounter with a letter string, a prelexical phonological code is created that is then compared with representations within a phonological lexicon. If one assumes that the prelexical phonological codes of early-acquired words are more easily accessed, this would explain why this class of words is accessed faster in a LDT. A similar account, the phonological completeness hypothesis, has been presented earlier (Brown \& Watson, 1987). If this account is correct, Gerhand and Barry's (1999) experiments demonstrate that this mechanism is very robust. These authors suggested an alternative explanation for their pattern of results: that the AoA effect is not localized at the level of phonological processing, but might affect all stages of word processing. This alternative account is the focus of the present study.

The central question in the present study is how we can test the prelexical phonological code hypotheses discussed earlier. There is evidence that at least some other factors are involved in AoA effects. In fact the true nature of AoA is still under discussion, and we do not pretend in the present paper to give the final answer or solution to the problem. Alternative accounts have been presented recently, such as semantic processing (Brysbaert, Van Wijnendaele, \& De Deyne, 2000), cumulative frequency (i.e., the total number of times a word has been encountered; see Lewis, Gerhand, \& Ellis, 2001), transfer of earlier-learned patterns (Zevin \& Seidenberg, 2002), and connectionistmodels (Ellis \& Lambon Ralph, 2000; Monaghan \& Ellis, 2002).

In this study, we tested assumptions from the phonological code hypothesis by manipulating AoA and word frequency in experiments using native speakers and late second-languagelearners. We chose late second-language learners because for these people, foreign language vocabulary was completed at a considerably later stage in life, and thus any item included in this vocabulary may be considered as late acquired. In any case, all words have been learned essentially from print and in an order corresponding with frequency of use in everyday practice rather than AoA. Moreover, all words were learned similarly, in terms of learning process. For this reason, it may be assumed that the vocabulary acquisition of a foreign language student sharply contrasts with the vocabulary acquisition of a native speaker, for whom vocabulary growth follows the course of cognitive development.

For this purpose, we compared the results of British subjects with those of advanced Dutch university students majoring in English. More specifically, we sought to replicate the well-established effects of word frequency and AoA with Dutch subjects for Dutch words controlled for concreteness, syllable structure, and word length. Our second and main purpose was to see how advanced Dutch university students would perform on the English set of words used in the Gerhand and Barry (1999) study.

Experimental research with late second-language learners might provide the answer to two as yet unresolved questions. First, such research might provide evidence for the involvement of phonology as the underlying factor in explaining AoA effects in word recognition. Second, such research might shed light on the question of whether frequency and AoA affect the same or different mechanisms or processing stages. In their recent study of picture naming, Meschyan and Hernandez (2002) proposed that both factors affect the same stage and are most likely the product of the same lexical process(es). This is consistent with the view of Ellis and Lambon Ralph (2000). Meschyan and Hernandez also proposed including late second-language learners in experimental studies. For these subjects, the lexical items would be learned late in life. Hence, frequency should play a strong role in lexical access, since words have been acquired primarily on the dimension of use, or frequency of occurrence. However, if early-learned concepts influence later learning, the mapping of these items onto already existing concepts should be easier if those concepts are more robust. If Ellis and Lambon Ralph are correct, we should expect to find the same pattern of effects as observed in early learners. Hence, AoA most likely also influences which lexical items have a head start, even for learners of a second language (Meschyan \& Hernandez, 2002).

In order to test these hypotheses, we conducted two experiments. Experiment 1 was designed to test and calibrate a set of Dutch experimental words selected with CELEX (Burnage, 1990) equivalent to the stimulus set used by Gerhand and Barry (1999). The goal of Experiment 1 was to determine whether similar results could be obtained with experimental words in which AoA and (CELEX) frequency were manipulated orthogonally. A major additional goal of Experiment 1 was to look for developmental effects. Our hypothesis was that the youngest subject group would show the largest AoA effects, because for these subjects the contrast between early- and late-acquired words would be largest. This effect is also predicted by the cumulative frequency hypothesis. In Experiment 2, our main goal was to test the central hypothesis developed in this study - that if the phonologicalcompleteness account is correct, late secondlanguage learners should not show any AoA effects. If, 
on the contrary, AoA effects are present, factors other than phonology may underlie these AoA effects in secondlanguage learners.

\section{EXPERIMENT 1}

\section{Method}

Subjects. Sixty-five subjects participated, consisting of three groups of readers varying in reading experience. There were 22 elementary school students (mean age 11 years, range 10-12) with 5 to 6 years of reading experience, 23 experienced readers recruited from the second year of a local secondary school (mean age 14 years, range 13-15), and 20 fifth-year students (mean age 17 years, range 16-18) recruited from the same secondary school. All subjects volunteered for participation and all had normal or correctedto-normal vision.

Stimulus materials. The stimulus set consisted of 160 items80 words and 80 pronounceable nonwords. Nonwords were matched on number of letters and syllables. The set was completed with 40 additional practice items. The set of 80 experimental words was factorially organized, as in the Gerhand and Barry (1999) set.

Design. The 80 experimental words were divided over the following four conditions: (1) early acquired high frequency (e.g., avond, baan); (2) early acquired, low frequency (e.g., drogen, hoest); (3) late acquired high frequency (e.g., arbeid, handel); and (4) late acquired low frequency (e.g., brons, dempen). The set is presented in Appendix A (see Appendix B for English translations). The AoA criterion was based on the Nieuwe Streeflijst, a Dutch reading acquisition norm list containing the vocabulary found in elementary school reading books (Kohnstamm, Schaerlaekens, de Vries, Akkerhuis, \& Froonincksx, 1981). The norms for this list were developed using experienced elementary schoolteachers. Early-acquired words were defined as those judged by $85 \%$ or more of the panel to belong to the standard vocabulary (active or passive) of a 6-year-old child. Late-acquired words were defined as those judged to have been acquired at the age of 6 by $50 \%$ or fewer of the judges of the panel (Kohnstamm et al., 1981) or words that even do not occur in the elementary school vocabulary list. Imageability criteria were based on Van Loon-Vervoorn's (1985) imageability norms. In the present study, $A o A$ was defined as the percentage of teachers in the Nieuwe Streeflijst panel claiming that a given word should be known by a 6-year-old child (Kohnstamm et al., 1981).

Apparatus. Stimuli were presented sequentially on the 14-in. color monitor of an IBM-compatible computer. The experiment was presented using the MEL program (Schneider, 1988). Stimuli were presented in white lowercase letters using MEL font Fr-25 on a black background. Individual letters measured $6 \mathrm{~mm}$ in height and 4-5 mm in width, tails (as in $j$ ) and flags (as in $d$ ) excluded. Two keys of the keyboard, the "z" and the slash "/", were assigned as "yes" (green) and "no" (red) keys in the right-handed version. For the left-handed version the reverse assignment was used.

Procedure. The experiment was run individually. The LDT was performed by pressing the "/" key on a keyboard with the index finger of the right hand in response to a real word and by pressing the " $z$ " key with the index finger of the left hand in response to a nonword. This response pattern was reversed, if requested, for lefthanded subjects. Before the experiment started, the subject was presented with 40 practice trials. Stimuli were presented in two blocks of 80 trials. There was a short break between the blocks. Stimuli were presented in random order in the center of the screen. Before the stimulus was presented, a fixation cross $(+)$ appeared for $500 \mathrm{msec}$ in the center of the screen. Then the stimulus was presented. When the subject responded (red or green key) within $5 \mathrm{sec}$, the stimulus disappeared from the screen. If a subject did not respond within $5 \mathrm{sec}$, the stimulus disappeared automatically and the response was registered as an incorrect trial. Intertrial interval was set at $1 \mathrm{sec}$. Decision latency was measured as the time elapsed between presentation of the stimulus and a response. The experiment took about $10 \mathrm{~min}$.

\section{Results}

Reaction time data. The data of Experiment 1 are presented in Table 1 . We conducted a 2 (frequency) $\times 2$ $($ AoA) $\times 3$ (group) mixed design analysis of variance (ANOVA) by subjects $\left(F_{\mathrm{s}}\right)$ and by items $\left(F_{\mathrm{i}}\right)$ on the reaction time (RT) dependent measure for correct responses. We used the items analysis to determine whether the significant effects we found with the subjects analysis were generalizable to other items not used in our experiment. We adopted an alpha level of .05 for all tests of significance. There was a main effect of group $\left[F_{\mathrm{s}}(2,62)=22.95, p<\right.$ $.001 ; F_{\mathrm{i}}(2,152)=281.28, p<.001 ; 882 \mathrm{msec}$ for elementary school, $658 \mathrm{msec}$ for second-year secondary school, and $560 \mathrm{msec}$ for fifth-year secondary school students], with all between-group differences being significant. There was a $79-\mathrm{msec}$ main effect of frequency $\left[F_{\mathrm{s}}(1,62)=49.2, p<.001 ; F_{\mathrm{i}}(1,76)=28.91, p<.001\right]$. There was a $74-\mathrm{msec}$ main effect of AoA $\left[F_{\mathrm{s}}(1,62)=\right.$ $\left.77.17, p<.001 ; F_{\mathrm{i}}(1,76)=25.09, p<.001\right]$, with earlyacquired words being processed faster. There was a frequency $\times$ AoA interaction $\left[F_{\mathrm{s}}(1,62)=7.49, p<.001\right.$; $\left.F_{\mathrm{i}}(1,76)=2.98, p<.088\right]$. The AoA effect was larger in low-frequency words (59 $\mathrm{msec}$ for high-frequency vs. $97 \mathrm{msec}$ for low-frequency words). There was a group $\times$ frequency interaction $\left[F_{\mathrm{s}}(2,62)=5.54, p<.006\right.$; $\left.F_{\mathrm{i}}(2,152)=8.92, p<.001\right]$, with elementary school students showing a larger frequency effect than that of fifthyear secondary school students (133 vs. $40 \mathrm{msec}$, respectively). There was an AoA $\times$ group interaction $\left[F_{\mathrm{s}}(2,62)=\right.$ $7.49, p<.001 ; F_{\mathrm{i}}(2,152)=6.68, p<.002$; Figure 1]

Figure 1 shows that AoA effects turned out to be largest in younger reader groups, with $121 \mathrm{msec}$ for elementary school $\left[F_{\mathrm{s}}(1,21)=24.00 p<.001\right], 71 \mathrm{msec}$ for second-year secondary school $\left[F_{\mathrm{s}}(1,22)=65.05, p<\right.$ $.001]$, and $38 \mathrm{msec}$ for fifth-year secondary school $\left[F_{\mathrm{s}}(1,19)=43.58, p<.001\right]$.

Accuracy data. Corresponding analyses of accuracy data produced a generally complementary picture, with the expected main effects of group $\left[F_{\mathrm{s}}(2,62)=4.56, p<\right.$ $.014 ; F_{i}(2,152)=11.43, p<.001 ; 10 \%$ error for elementary vs. $7 \%$ for second year vs. $5 \%$ for fifth year], frequency $\left[F_{\mathrm{s}}(1,62)=42.36, p<.001 ; F_{\mathrm{i}}(1,76)=8.03, p<\right.$

Table 1

Reaction Times (in Milliseconds) and Percentage Error (PE) in Elementary, Second-Year Secondary, and Fifth-Year Secondary School Students, Experiment 1

\begin{tabular}{|c|c|c|c|c|c|c|}
\hline \multirow[b]{2}{*}{ Grade } & \multicolumn{2}{|c|}{ Elementary School } & \multicolumn{2}{|c|}{ Second Year } & \multicolumn{2}{|c|}{ Fifth Year } \\
\hline & RT & $\mathrm{PE}$ & RT & $\overline{P E}$ & RT & $\overline{\mathrm{PE}}$ \\
\hline $\mathrm{HF} /$ Early & 770 & 3.6 & 597 & 3.5 & 523 & 3.0 \\
\hline $\mathrm{HF} /$ Late & 860 & 9.3 & 649 & 4.6 & 557 & 5.0 \\
\hline LF/Early & 872 & 5.9 & 646 & 4.1 & 560 & 5.0 \\
\hline LF/Late & 1,024 & 22.5 & 739 & 15.4 & 601 & 8.3 \\
\hline
\end{tabular}

Note-HF, high frequency; LF, low frequency. 


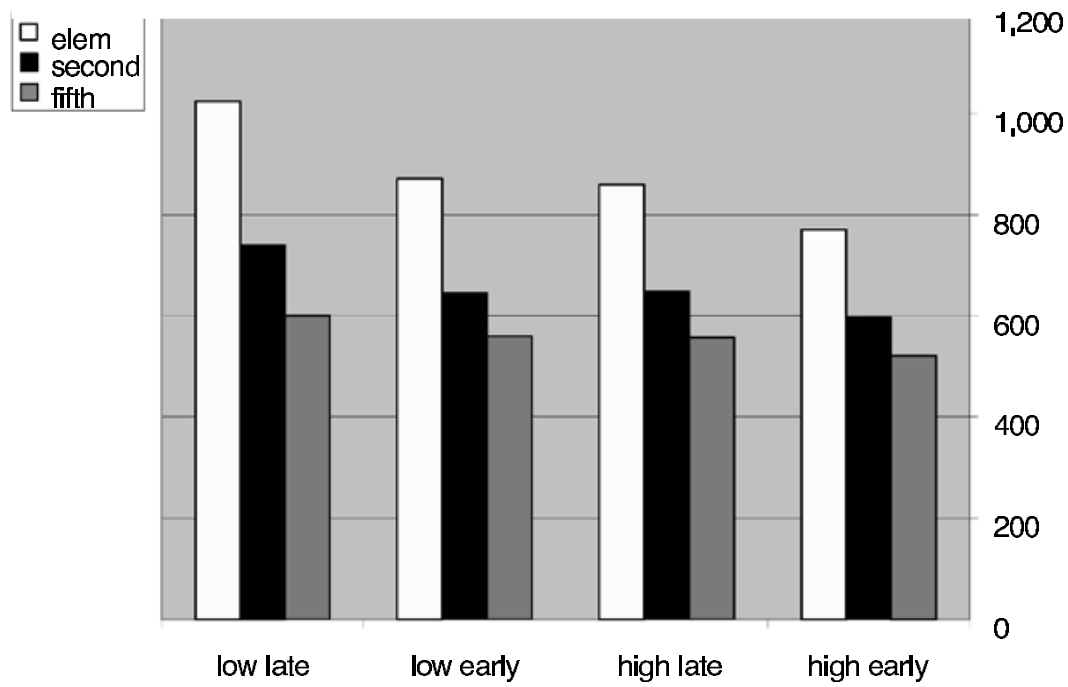

Figure 1. Group $\times$ AoA interaction, Experiment 1.

.006 ; $5 \%$ error on high frequency vs. $10 \%$ for low frequency $]$, and $\operatorname{AoA}\left[F_{\mathrm{s}}(1,62)=51.13, p<.001\right.$; $F_{\mathrm{i}}(1,76)=12.32, p<.001 ; 4 \%$ error on early acquired vs. $11 \%$ on late acquired], and a frequency $\times$ AoA interaction $\left[F_{\mathrm{s}}(1,64)=25.25, p<.001 ; F_{\mathrm{i}}(1,76)=3.87, p<\right.$ .053 ], with a stronger AoA effect in low-frequency words (3\% for high vs. $11 \%$ for low). All effects were in line with the pattern found for decision latency data. To conserve space, uninformative interactions with group are omitted.

\section{Discussion}

Experiment 1 demonstrates that the results reported by Gerhand and Barry (1999) can be replicated with Dutch subjects and words. These results also confirm experiments reported earlier by Brysbaert and his colleagues (Brysbaert, Lange, \& Van Wijnendaele, 2000). Our results show that reliable frequency and AoA effects can be obtained in Dutch.

A second and perhaps even more interesting outcome of Experiment 1 is the AoA $\times$ group interaction. Our data, collected from a wide range of age groups, clearly support the cumulative frequency hypothesis (Lewis et al., 2001), which posits that AoA effects can be explained by assuming that early- and late-acquired words differ in their frequency history. ${ }^{1}$ This would imply that early and late words are more similar in cumulative frequency for adults than they are for children. Exactly this pattern of results is reflected in our data. Although this is not a definitive proof for the correctness of the cumulative frequency hypothesis, it is at least strong evidence in support of it.

In order to further test the hypotheses regarding the involvement of prelexical phonologicalcodes, we conducted an experiment involving native speakers of Dutch with fluent command of English as their second language as well as native speakers from the United Kingdom. The goal of this experiment was to compare the performance of fluent speakers of English with that of a control group of British English subjects, again using the Gerhand and Barry (1999) set. We hypothesized, in support of the phonological completeness account, that late secondlanguage learners would not show any AoA effects.

\section{EXPERIMENT 2}

\section{Method}

Subjects. A group of 53 subjects participated in Experiment 2. This group consisted of 22 graduate students of English (6 male and 16 female) at Utrecht University with Dutch as their native language. All subjects had learned English as a foreign language in secondary education. Dutch secondary education starts at the age of about 12 to 13 years. All subjects could read fluently, both in Dutch and in English. The remaining 31 subjects were British citizens (3 males and 28 females), students at the University of Birmingham; all subjects reported either unaided or corrected vision. Each subject was paid for his/her participation.

Materials. The LDT consisted of the Gerhand and Barry (1999) stimulus set. This set is presented in Appendix C (see Appendix D for English translations). The same set was presented to the Dutch and the British subjects.

Procedure. Stimulus presentation was the same as described for Experiment 1. Both experiments were prepared and presented using MEL (Schneider, 1988).

\section{Results}

Reaction time data. The data of Experiment 2 are presented in Table 2 . We conducted a 2 (frequency) $\times 2$ $($ AoA $) \times 2$ (British/Dutch) mixed design ANOVA by subjects $\left(F_{\mathrm{s}}\right)$ and by items $\left(F_{\mathrm{i}}\right)$ on the reaction time (RT) dependent measure for correct responses. This analysis showed a 94-msec main effect of group $\left[F_{\mathrm{s}}(1,51)=6.02\right.$, $\left.p<.006 ; F_{\mathrm{i}}(1,60)=107.55, p<.001\right]$, with British subjects being faster. There was a $144-\mathrm{msec}$ main effect of fre- 
Table 2

Reaction Times (RTs, in Milliseconds) and Percentage Error (PE) by Native Speakers and Second-Language Learners, Experiment 2

\begin{tabular}{llllll}
\hline & \multicolumn{2}{l}{ Native Speakers } & & \multicolumn{2}{c}{ Second-Language Learners } \\
\cline { 2 - 3 } \cline { 5 - 6 } Grade & RT & PE & & RT & PE \\
\hline HF/Early & 583 & 0.13 & & 675 & 0.13 \\
HF/Late & 632 & 0.26 & 691 & 0.14 \\
LF/Early & 661 & 0.55 & & 786 & 1.45 \\
LF/Late & 812 & 2.70 & & 913 & 3.86 \\
\hline
\end{tabular}

Note-HF, high frequency; LF, low frequency.

quency $\left[F_{\mathrm{s}}(1,51)=86.24, p<.001 ; F_{\mathrm{i}}(1,60)=98.47, p<\right.$ $.001]$, with high-frequency words having shorter decision latencies. There was a $88-\mathrm{msec}$ main effect of AoA $\left[F_{\mathrm{s}}(1,51)=43.43, p<.001 ; F_{\mathrm{i}}(1,60)=28.94, p<.001\right]$, with early-acquired words eliciting faster decisions. There was a frequency $\times$ AoA interaction effect $\left[F_{\mathrm{s}}(1,51)=\right.$ $\left.25.11, p<.001 ; F_{\mathrm{i}}(1,60)=11.11, p<.001\right]$, with the AoA effect being largest in the low-frequency condition ( $35 \mathrm{msec}$ for high frequency vs. $140 \mathrm{msec}$ for low frequency). Interestingly, there were no additional interactions of AoA with group, nor any higher order interactions.

Accuracy data. We also computed a 2 (frequency) $\times$ $2($ AoA $) \times 2$ (British/Dutch) mixed design ANOVA by subjects $\left(F_{\mathrm{s}}\right)$ and by items $\left(F_{\mathrm{i}}\right)$ on accuracy data. This analysis produced largely a mirror of the latency data. There was a main effect of group $\left[F_{\mathrm{s}}(1,51)=5.20, p<\right.$ $\left..027 ; F_{\mathrm{i}}(1,60)=3.48, p<.067\right]$. British subjects were more accurate $(0.9 \%$ vs. $1.36 \%$ for Dutch students). There was a main effect of frequency $\left[F_{\mathrm{s}}(1,51)=136.58\right.$, $\left.p<.001 ; F_{\mathrm{i}}(1,60)=18.33, p<.001\right]$, with lowfrequency words being processed less accurately $(2.05 \%$ for low frequency vs. $0.1 \%$ for high frequency). There was a main effect of AoA $\left[F_{\mathrm{s}}(1,51)=94.19, p<.001\right.$; $\left.F_{\mathrm{i}}(1,60)=6.56, p<.013\right]$. Early-acquired words elicited fewer errors $(0.46 \%$ vs. $1.69 \%$ for late acquired). There was an AoA $\times$ frequency interaction $\left[F_{\mathrm{s}}(1,51)=71.49\right.$, $\left.p<.001 ; F_{\mathrm{i}}(1,60)=5.41, p<.023\right]$, with the AoA effect being larger in low-frequency words $(1.14 \% \mathrm{vs}$. $0.1 \%$ ). Finally, there was a group $\times$ frequency interaction $\left[F_{\mathrm{s}}(1,51)=16.51, p<.002 ; F_{\mathrm{i}}(1,60)=5.19, p<\right.$ .026]. Dutch subjects were less accurate on low-frequency words ( $2.65 \%$ errors vs. $1.62 \%$ for the British group).

\section{DISCUSSION}

The two experiments reported in this paper contribute to the growing stream of publications dealing with the issue of how word frequency is related to AoA and how these factors cooperate in skilled word recognition, as well as in the developing mental lexicon. The research evidence is still inconclusive in many respects. Three major theoretical accounts for explaining AoA dominate the literature: (1) the phonological codes account (Brown \& Watson, 1987; Gerhand \& Barry, 1999), (2) the cumulative frequency account (Lewis et al., 2001), and (3) the connectionist network approach (Ellis \& Lambon Ralph,
2000; Zevin \& Seidenberg, 2002). We discuss our results in light of these accounts.

A more general preliminary conclusion is that Experiment 1 confirms that AoA results reported mainly in the English language domain are reliable and can be replicated with Dutch subjects and words. Experiment 1 also confirms earlier experiments reported by Brysbaert and colleagues (Brysbaert, Lang, \& Van Wijnendaele, 2000). A theoretically even more important effect is that established AoA effects proved to be largest in the youngest subject group. It should be noted that our data are based on experimental words selected on CELEX frequency, which makes these results less vulnerable to earlier criticism by Zevin and Seidenberg (2002) regarding the relative insensitive frequency norms of the set used in the study by Gerhand and Barry (1999).

The most striking result reported in Experiment 2 is that skilled second-language learners produced the same patterns of responses in the LDT presented in Experiment 2 . This is contrary to predictions of the phonological completeness hypothesis (Brown \& Watson, 1987). For late second-language learners, all words are acquired late, so it is difficult to see how prelexical phonological codes might affect the process of visual word recognition. A proponent of the phonological code hypothesis might try to argue against this line of thought by claiming that Dutch words show a certain overlap in spelling with English words and also, be it to a smaller extent, in pronunciation. We would like to reject this idea by arguing that although Dutch words sometimes look similar to their English counterparts, they are quite dissimilar if their phonological properties are considered in more detail. If there is an overlap, it must be located at the level of orthography, not at the level of phonology, and a more reasonable explanation would be to locate the AoA effect at the level of meaning. Familiar patterns in the spellings of words might have triggered corresponding semantic representations. This is exactly the mechanism where current connectionist accounts of word recognition (e.g., Zevin \& Seidenberg, 2002) locate AoA effects.

A second alternative account of our results is in terms of cumulative frequency. The cumulative frequency account explains AoA effects in terms of frequency of use in human development. Lewis et al. (2001) recently suggested that cumulative frequency might be a preferable and more parsimonious account of the AoA effects reported in earlier investigations. The simple and intuitively attractive account is that early-learned words have been known for a longer time and will have been perceived more often. According to Lewis et al., the reason for the premature rejection of the cumulative frequency hypothesis was an initial failure to find statistical interactions between frequency and AoA effects. Lewis et al. have argued that this was a premature decision, and with a reanalysis of earlier data they have provided support for this hypothesis.

Although our results cannot be considered as definitive evidence against a cumulative frequency account, 
we think it should be taken as the least probable account at best. Evidence for the cumulative frequency hypothesis was found in Experiment 1, where the youngest subject group showed the largest AoA effect. However, Experiment 1 data alone do not enable us to discriminate between the cumulative account and alternative accounts at this point. Therefore, it is necessary to include the results of Experiment 2 in this discussion. It is difficult to see how the cumulative frequency account could explain effects in late second-language learners, unless some kind of transfer mechanism is postulated to work in the mental lexicon.

Our Experiment 2 results are particularly challenging for the phonological completeness hypothesis and confirm earlier reported negative evidence (Monaghan \& Ellis, 2002). Our data suggest that the order of acquisition remains an important determinant of lexical access. The question is how acquisition order might have worked in our second-language subjects in Experiment 2. There are two possibilities:(1) Acquisition order in early life is replicated in the vocabulary acquisition process of a secondlanguage learner, and (2) AoA effects in second-language learners are partially mediated by native language vocabulary. A combination of both options is also possible. It is evident that the degree of relatedness between native and foreign language determines the impact of first-language mediation. In particular, the occurrence of cognate words 2 in both vocabularies might be expected to be a critical factor. For this reason, a listing of cognate word forms for Experiment 2 is presented in Appendix C. We suggest that the number of cognates is sufficiently large to propose semantic mediation by the first (native) language route as a good candidate for explaining the results.

Taken together, we think that the present data fit in a semantic account of the source of AoA effects in lexical decision. The effect of AoA in late second-language learners can be explained in an elegant and parsimonious way by assuming that AoA in late second-language learners is mediated by the overlapping or corresponding meanings of the early- and late-acquired words in the native and foreign languages involved. This does not imply that possible effects of phonology are denied, but rather that in our studies, phonology cannot be considered the decisive factor. Our hypothesis can readily be tested with experiments including subjects varying in native and foreign language skill, varying in second-language acquisition age, and varying in relatedness between the languages involved. This is in agreement with earlier studies focusing on the origin of AoA (Brysbaert et al., 2000), who concluded their paper with the suggestion that the locus of AoA effects may have been interpreted too narrowly.

Our data confirm the results reported by Izura and Ellis (2002) in the first and second languages of dominant Spanish/English bilinguals, both in picture naming and lexical decision. However, Izura and Ellis operationalized AoA very differently. Rather than using ratings from native speakers, they examined tex tbooks used in English language courses and determined AoA on the basis of the order in which those words appeared in the textbooks. Thus the AoA effect they found was likely to reflect an effect of the order in which words were learned. Interestingly, they found that lexical decision speed in the second language was predicted by the acquisition order in that second language, not by the order in the native language equivalents. They concluded that this is difficult to reconcile with a simple semantic theory of AoA effects. Because of the large differences in focus and experimental method, the present experiments must be considered as further contributions to a converging database of empirical evidence. A major difference in this respect is the linguistic relationship between native and second languages involved in the two studies.

However, it is conceivable that AoA effects in secondlanguage learners are dependent on the linguistic relationships between native (L1) and foreign (L2) language vocabularies. If the $\mathrm{L} 1$ and $\mathrm{L} 2$ vocabularies systems are unrelated (such as in Arabic and English, with no or few cognate words), it may be anticipated that AoA effects are not or are only marginally mediated by the (L1) vocabulary system. This was also found in the study of Izura and Ellis (2002). For cognate languages, such as English and Dutch, this state of affairs probably differs; L1 and L2 systems will interact (or interfere) more freely. In sum, we follow Izura and Ellis, who proposed the revised hierarchical model (Kroll \& Stewart, 1994) as a possible account of their data.

According to Kroll and Stewart's (1994) model, in the course of learning a second language, L1 and L2 connections (orthographic, phonological, and semantic) are established, and the quality of these associations is strongly determined by the transparency of the L1-L2 relationships. Therefore it is significant that in Appendix A of our study, the number of cognate words was larger than that in the Spanish/English set used by Izura and Ellis (2002). Since most English words differ phonologically and orthographically from their Dutch equivalents, we assume that meaning is a major determinant of the lexical decision speed data found in our Experiment 2. In sum, any second-language lexical decision study will be affected strongly by two major factors: linguistic relatedness and language development of the subjects.

Connectionist network approaches explain AoA age effects in terms of reduction in network plasticity, causing failure to differentiate late items (Ellis \& Lambon Ralph, 2000) or in terms of differential learning patterns (Zevin \& Seidenberg, 2002). According to the latter account, AoA effects occur when what is learned about early patterns does not carry over to later ones. Zevin and Seidenberg (2002) are cautious in generalizing the data they have collected in simulation studies to natural languagelearning situations. They are correct when they state that natural language learning involves learning mappings between phonology and semantics.

Skilled reading often involves computations from orthography to phonology to semantics. The age at which children learn phonology to semantics mappings thus might affect the organization of the mental lexicon in this 
manner. Earlier in this discussion, we argued that the data of Experiment 2 clearly provide evidence for this possibility. The extent to which connectionist models can provide us with simulations and models that enable us to model the orthographic $\rightarrow$ phonologic $\rightarrow$ semantic mappings that are created during the process of learning a natural language vocabulary in human development remains to be determined.

We suggest further exploration of the semantic hypothesis by conducting cross-language experiments varying orthographic transparency in terms of sound-letter mappings (Plaut, McClelland, Seidenberg, \& Patterson, 1996). We predict that languages with inconsistent spellings should produce larger AoA effects, and that this effect should also be found in late second-language learners, as was demonstrated in our study.

\section{REFERENCES}

Batyen, R. H., Piepenbrock, T., \& van Rijn, H. (1993). The Celex lexical database (CD-ROM). Philadelphia: University of Pennsylvania, Linguistic Data Consortium.

Barry, C., Morrison, C. M., \& Ellis, A. W. (1997). Naming the Snodgrass and Vanderwart pictures: Effects of age of acquisition, frequency and name agreement. Quarterly Journal of Experimental Psychology, 50A, 560-585.

Brown, G. D. A., \& WATSON, F. L. (1987). First in, first out: Word learning age and spoken word frequency as predictors of word familiarity and word naming frequency. Memory \& Cognition, 15, 208-216.

Brysbaert, M., Lange, M., \& Van Wijnendaele, I. (2000). The effects of age-of-acquisition and frequency-of-occurrence in visual word recognition: Further evidence from the Dutch language. European Journal of Cognitive Psychology, 12, 65-85.

Brysbaert, M., Van Wijnendaele, I., \& De Deyne, S. (2000). Ageof-acquisition effects in semantic processing tasks. Acta Psychologica, 104, 215-226.

Burnage, G. (1990). CELEX: A guide for users. Nijmegen: CELEX.

Ellis, A. W., \& Lambon Ralph, M. A. (2000). Age of acquisition effects in adult lexical processing reflects loss of plasticity in maturing systems: Insights from connectionist networks. Journal of Experimental Psychology: Learning, Memory, \& Cognition, 26, 1103-1123.

Ellis, A. W., \& Morrison, C. M. (1998). Real age-of-acquisition effects in lexical retrieval. Journal of Experimental Psychology: Learning, Memory, \& Cognition, 24, 515-523.

GERHAND, S., \& BARRY, C. (1998). Word frequency effects in oral reading are not merely age-of-acquisition effects in disguise. Journal of Experimental Psychology: Learning, Memory, \& Cognition, 24, 267-283.

Gerhand, S., \& BARry, C. (1999). Age of acquisition, word frequency, and the role of phonology in the lexical decision task. Memory \& Cognition, 27, 592-602.

Gilhooly, K. J., \& LogIE, R. H. (1980). Age-of-acquisition, imagery, concreteness, familiarity, and ambiguity measures for 1,944 words. Behavior Research Methods \& Instrumentation, 12, 395-427.

Gilhooly, K. J., \& Logie, R. H. (1982). Word age-of-acquisition and lexical decision making. Acta Psychologica, 50, 21-34.

Gilhooly, K. J., \& Watson, F. L. (1981). Word age-of-acquisition effects: A review. Current Psychological Research, 1, 215-226.

Harley, T. (2001). The psychology of language. New York: Taylor \& Francis.

IzURA, C., \& ElLis, A. E. (2002). Age of acquisition effects in word recognition and production in first and second languages. Psicológica, 23, 245-281.

Kohnstamm, G. A., Schaerlaekens, A. M., de Vries, A. K., AkkerHUIS, G. W., \& FroonincksX, M. F. (1981). Nieuwe streeflijst woordenschat voor 6-jarigen [New target vocabulary list for 6-year-old children]. Lisse: Swets \& Zeitlinger.

Kroll, J. F., \& Stewart, E. (1994). Category interference in transla- tion and picture naming: Evidence for asymmetric connections between bilingual memory representations. Journal of Memory \& Language, 33, 149-174.

KuČERA, H., \& Francis, W. (1967). Computational analysis of presentday American English. Providence: Brown University Press.

Lewis, M. B., Gerhand, S., \& Ellis, H. D. (2001). Re-evaluating ageof-acquisition effects: Are they simply cumulative-frequency effects? Cognition, 78, 189-205.

Lukatela, G., \& Turvey, M. T. (1994a). Visual lexical access is initially phonological: 1 . Evidence from associative priming by words, homophones, and pseudohomophones. Journal of Experimental Psychology: General, 123, 107-128.

Lukatela, G., \& Turvey, M. T. (1994b). Visual lexical access is initially phonological: 2. Evidence from phonological priming by homophones and pseudohomophones. Journal of Experimental Psychology: General, 123, 331-353.

Meschyan, G., \& Hernandez, A. (2002). Age of acquisition and word frequency: Determinants of object-naming speed and accuracy. Memory \& Cognition, 30, 262-269.

Monaghan, J., \& Ellis, A. W. (2002). Age of acquisition and the completeness of phonological representation. Reading \& Writing, 15, 759-788.

Morrison, C. M., \& Ellis, A. W. (1995). Roles of word frequency and age of acquisition in word naming and lexical decision. Journal of Experimental Psychology: Learning, Memory, \& Cognition, 21, 116133.

Morrison, C. M., Ellis, A. W., \& Quinlan, P. T. (1992). Age of acquisition, not word frequency, affects object naming, not object recognition. Memory \& Cognition, 20, 705-714.

MoRTON, J. (1969). Interaction of word information in word recognition. Psychological Review, 76, 165-178.

Plaut, D. C., McClelland, J. L., Seidenberg, M. S., \& Patterson, K. (1996). Understanding normal and impaired reading: Computational principles in quasi-regular domains. Psychological Review, 103, 56115.

SCHNEIDER, W. (1988). Micro experimental laboratory user's guide: Computer techniques for real time experimental experimentation. Pittsburgh: Psychology Software Tools.

SeidenberG, M. S., \& McClelland, J. L. (1989). A distributed, developmental model of word recognition and naming. Psychological Review, 96, 523-568.

Turner, J. E., Valentine, T., \& Ellis, A. W. (1998). Contrasting effects of age of acquisition and word frequency on auditory and visual lexical decision. Memory \& Cognition, 26, 1282-1291.

VAN LOON-VERVOORN, W. A. (1985). Voorstelbaarheidswaarden van Nederlandse woorden [Imageability norms for Dutch words]. Lisse: Swets \& Zeitlinger.

VAN ORden, G. C. (1987). A ROWS is a ROSE: Spelling, sound, and reading. Memory \& Cognition, 15, 181-198.

VAN ORden, G. C., \& Goldinger, S. D. (1994). Interdependence of form and function in cognitive systems explains perception of printed words. Journal of Experimental Psychology: Human Perception \& Performance, 20, 1269-1291.

Zevin, J. D., \& Seidenberg, M. S. (2001). Cumulative frequency affects reading aloud; frequency trajectory does not. Manuscript submitted for publication.

ZEvin, J. D., \& Seidenberg,M. S. (2002). Age of acquisition effects in word reading and other tasks. Journal of Memory \& Language, 47, $1-29$.

\section{NOTES}

1. We deliberately use the term frequency history in order to distinguish it from the term frequency trajectory (Zevin \& Seidenberg, 2001). These authors define frequency trajectory as how exposures to a word are distributed over time. Cumulative frequency refers to the total number of exposures to a word.

2. Cognate words are usually defined as words in different languages that have the same root and meaning and which look similar (Harley, 2001). This definition leaves room to some differences of interpretation. It is clear that individual words differ on the similarity dimension. 
APPENDIX A

Stimulus Set, Experiment 1

\begin{tabular}{|c|c|c|c|c|c|c|c|c|c|c|c|}
\hline Stimulus & $\mathrm{F}$ & AoA & IS & $\mathrm{L}$ & NS & Stimulus & $\mathrm{F}$ & AoA & IS & $\mathrm{L}$ & NS \\
\hline \multicolumn{6}{|c|}{ High Frequency, Early Acquired } & \multicolumn{6}{|c|}{ High Frequency, Late Acquired } \\
\hline avond & 195 & 98 & 5.16 & 5 & 2 & arbeid & 75 & 27 & 4.87 & 6 & 2 \\
\hline baan & 52 & 88 & 4.33 & 4 & 1 & contact & 125 & 21 & 5.20 & 7 & 2 \\
\hline brengen & 171 & 98 & 4.73 & 7 & 2 & generaal & 57 & 40 & 5.60 & 8 & 3 \\
\hline droom & 80 & 94 & 5.27 & 5 & 1 & handel & 57 & $*$ & 4.63 & 6 & 2 \\
\hline honger & 50 & 98 & 4.33 & 6 & 2 & jeugd & 63 & $*$ & 4.80 & 5 & 1 \\
\hline leggen & 63 & 98 & 5.36 & 6 & 2 & lid & 114 & 25 & 4.38 & 3 & 1 \\
\hline meester & 61 & 94 & 5.40 & 7 & 2 & lot & 54 & $*$ & 5.13 & 3 & 1 \\
\hline midden & 59 & 97 & 5.06 & 6 & 2 & minister & 93 & 31 & 5.90 & 8 & 3 \\
\hline nacht & 191 & 98 & 5.87 & 5 & 1 & persoon & 108 & 47 & 5.57 & 7 & 2 \\
\hline oom & 106 & 98 & 5.90 & 3 & 1 & reeks & 55 & $*$ & 4.10 & 5 & 1 \\
\hline plezier & 62 & 97 & 4.21 & 7 & 2 & roman & 55 & $*$ & 5.47 & 5 & 2 \\
\hline prijs & 75 & 98 & 4.77 & 5 & 1 & sfeer & 61 & $*$ & 4.10 & 5 & 1 \\
\hline smaak & 75 & 89 & 3.80 & 5 & 1 & strijd & 119 & 38 & 4.57 & 6 & 1 \\
\hline verdriet & 54 & 97 & 4.47 & 8 & 2 & tekst & 61 & $*$ & 4.47 & 5 & 1 \\
\hline voelen & 62 & 90 & 4.83 & 6 & 2 & terrein & 84 & $*$ & 4.60 & 7 & 2 \\
\hline wind & 106 & 97 & 4.93 & 4 & 1 & trekken & 65 & 46 & 5.97 & 7 & 2 \\
\hline zetten & 55 & 93 & 4.67 & 6 & 2 & vlak & 95 & 46 & 5.00 & 4 & 1 \\
\hline zomer & 68 & 97 & 5.67 & 5 & 2 & volk & 122 & 35 & 4.96 & 4 & 1 \\
\hline zorgen & 51 & 92 & 4.23 & 6 & 2 & vormen & 58 & 47 & 4.87 & 6 & 2 \\
\hline zuster & 79 & 97 & 6.07 & 6 & 2 & zijde & 57 & 28 & 5.58 & 5 & 2 \\
\hline$M$ & 85.75 & 95.40 & 4.95 & 5.60 & 1.65 & $M$ & 78.90 & 21.55 & 4.99 & 5.60 & 1.65 \\
\hline$S D$ & 46.04 & 3.32 & 0.63 & 1.19 & 0.49 & $S D$ & 26.05 & 19.43 & 0.56 & 1.47 & 0.67 \\
\hline
\end{tabular}

Low Frequency, Early Acquired

\begin{tabular}{|c|c|c|c|c|c|c|c|c|c|c|c|}
\hline & & & & & & & & & & & \\
\hline carnaval & 3 & 90 & 5.90 & 8 & 3 & brons & 3 & $*$ & 4.90 & 5 & 1 \\
\hline drogen & 4 & 94 & 4.21 & 6 & 2 & buffel & 2 & $*$ & 5.50 & 6 & 2 \\
\hline gil & 5 & 97 & 4.03 & 3 & 1 & dempen & 1 & $*$ & 5.03 & 6 & 2 \\
\hline hamster & 1 & 90 & 6.03 & 7 & 2 & fooi & 4 & $*$ & 5.23 & 4 & 1 \\
\hline hoest & 3 & 96 & 4.73 & 5 & 1 & fortuin & 2 & $*$ & 5.10 & 7 & 2 \\
\hline klikken & 1 & 98 & 4.27 & 7 & 2 & gen & 2 & $*$ & 4.40 & 3 & 1 \\
\hline knal & 5 & 94 & 4.70 & 4 & 1 & gif & 5 & $*$ & 4.43 & 3 & 1 \\
\hline liedje & 5 & 100 & 5.23 & 6 & 2 & glippen & 2 & 32 & 4.97 & 7 & 2 \\
\hline lusten & 1 & 96 & 3.43 & 6 & 2 & kolom & 4 & $*$ & 5.60 & 5 & 2 \\
\hline mop & 3 & 92 & 4.33 & 3 & 1 & peinzen & 2 & 21 & 4.93 & 7 & 2 \\
\hline pesten & 2 & 96 & 4.70 & 6 & 2 & pleiten & 3 & $*$ & 4.57 & 7 & 2 \\
\hline peuter & 2 & 88 & 5.73 & 6 & 2 & saldo & 4 & $*$ & 5.07 & 5 & 2 \\
\hline plons & 2 & 96 & 4.73 & 5 & 1 & schaak & 1 & $*$ & 4.81 & 6 & 1 \\
\hline puzzel & 3 & 93 & 5.77 & 6 & 2 & schemer & 4 & $*$ & 4.37 & 7 & 2 \\
\hline rem & 4 & 97 & 4.33 & 3 & 1 & sprint & 2 & $*$ & 5.27 & 6 & 1 \\
\hline scheur & 3 & 97 & 5.90 & 6 & 1 & tiran & 3 & $*$ & 4.80 & 5 & 2 \\
\hline slingers & 2 & 93 & 6.07 & 8 & 2 & toernooi & 1 & $*$ & 5.13 & 8 & 2 \\
\hline spuug & 2 & 92 & 4.93 & 5 & 1 & vlies & 4 & 23 & 5.33 & 5 & 1 \\
\hline stroop & 3 & 89 & 5.67 & 6 & 1 & werf & 2 & $*$ & 5.53 & 4 & 1 \\
\hline zeuren & 3 & 93 & 4.13 & 6 & 2 & zuivel & 4 & $*$ & 4.93 & 6 & 2 \\
\hline$M$ & 2.85 & 94.05 & 4.94 & 5.60 & 1.60 & $M$ & 2.75 & 3.80 & 5.00 & 5.60 & 1.60 \\
\hline$S D$ & 1.27 & 3.24 & 0.79 & 1.47 & 0.60 & $S D$ & 1.21 & 9.47 & 0.36 & 1.39 & 0.50 \\
\hline
\end{tabular}

Note-F, frequency in 1 million words (CELEX; Burnage, 1990; Baayen, Piepenbrock \& Van Rijn, 1993). AoA, age of acquisition in percentage of teachers who claim that this word should be known by a 6-year-old child (Kohnstamm, Schaerlaekens, de Vries, Akkerhuis, \& Froonincksx, 1981). Asterisk (*) indicates that the word does not occur in the Kohnstamm et al. (1981) list. IS, imageability expressed on a 7-point scale (imageability norms for Dutch words; Van Loon-Vervoorn, 1985). L, word length in number of letters. NS, number of syllables. 
APPENDIX B

Translation of Dutch Words Used in Experiment 1

\begin{tabular}{|c|c|c|c|}
\hline High/Early & High/Late & Low/Early & Low/Late \\
\hline avond & arbeid & carnaval* & brons* \\
\hline evening & labour & carnival & bronze \\
\hline baan & contact* & drogen* & buffel* \\
\hline job & contact & dry & buffalo \\
\hline brengen* & generaal* & gil & dempen \\
\hline bring & general & yell & fillup \\
\hline droom* & handel & hamster* & fooi \\
\hline dream & trade & hamster & tip \\
\hline honger* & jeugd & hoest & fortuin* \\
\hline hunger & youth & cough & fortune \\
\hline leggen & lid & klikken* & gen* \\
\hline put & member & click & gene \\
\hline meester & lot & knal & gif \\
\hline lord & fate & bang & poison \\
\hline midden* & minister* & liedje & glippen \\
\hline middle & minister & song & slip \\
\hline nacht* & persoon* & lusten & kolom* \\
\hline night & person & like & column \\
\hline oom & reeks & mop & peinzen \\
\hline uncle & series & joke & ponder \\
\hline plezier & roman & pesten* & pleiten \\
\hline fun & novel & pester & plead \\
\hline prijs & sfeer* & peuter & saldo \\
\hline award & atmosphere & toddler & balance \\
\hline smaak & strijd & plons & schaak \\
\hline taste & struggle & splash & chess \\
\hline verdriet & tekst* & puzzle* & schemer \\
\hline sorrow & text & puzzle & twilight \\
\hline voelen & terrein & rem & sprint* \\
\hline feel & territory & brake & sprint \\
\hline wind* & trekken & scheur & $\operatorname{tiran} *$ \\
\hline wind & draw & tear & tyrant \\
\hline zetten & vlak & slingers & toernooi* \\
\hline posit & surface & festoon & tournament \\
\hline zomer* & volk & spuug & vlies \\
\hline summer & people & spit & membrane \\
\hline zorgen & vormen & stroop* & werf* \\
\hline care & shape & syrup & wharf \\
\hline zuster* & zijde* & zeuren & zuivel \\
\hline sister & side & whine & dairy \\
\hline
\end{tabular}

*Cognate form. 
APPENDIX C

Stimulus Set, Experiment 2

\begin{tabular}{|c|c|c|c|c|c|c|c|c|c|c|c|}
\hline Stimulus & $\mathrm{KF}$ & Con & Imag & AoA & $\mathrm{L}$ & Stimulus & $\mathrm{KF}$ & Con & Imag & AoA & $\mathrm{L}$ \\
\hline \multicolumn{6}{|c|}{ High Frequency, Early Acquired } & \multicolumn{6}{|c|}{ High Frequency, Late Acquired } \\
\hline men & 763 & 5.86 & 5.87 & 2.36 & 3 & student & 131 & 5.48 & 6.03 & 4.81 & 7 \\
\hline step & 131 & 5.08 & 4.83 & 2.67 & 4 & union & 182 & 4.49 & 5.26 & 5.03 & 5 \\
\hline breakfast & 53 & 5.76 & 5.86 & 2.33 & 9 & sex & 84 & 5.12 & 5.84 & 4.5 & 3 \\
\hline fight & 98 & 4.55 & 5.43 & 2.61 & 5 & novel & 59 & 5.29 & 5.47 & 4.75 & 5 \\
\hline page & 66 & 5.71 & 5.55 & 2.67 & 4 & mass & 110 & 3.97 & 4.84 & 4.58 & 4 \\
\hline march & 120 & 4.4 & 4.97 & 2.69 & 5 & moral & 142 & 2.2 & 3.41 & 5.39 & 5 \\
\hline weather & 69 & 4.39 & 5.37 & 2.92 & 7 & text & 60 & 4.98 & 4.37 & 4.86 & 4 \\
\hline win & 55 & 3.64 & 4.54 & 2.69 & 3 & secretary & 191 & 5.76 & 5.63 & 4.56 & 9 \\
\hline shoulder & 61 & 5.89 & 5.77 & 2.64 & 8 & science & 131 & 3.66 & 4.23 & 4.58 & 7 \\
\hline find & 399 & 3.51 & 3.7 & 2.72 & 4 & industry & 171 & 4.79 & 4.99 & 4.92 & 8 \\
\hline land & 217 & 6.04 & 5.66 & 2.86 & 4 & president & 382 & 5.26 & 5.72 & 4.58 & 9 \\
\hline newspaper & 65 & 5.76 & 6.16 & 2.92 & 9 & income & 109 & 4.29 & 4.75 & 5.06 & 6 \\
\hline close & 234 & 3.91 & 4.2 & 2.83 & 5 & rate & 209 & 3.08 & 3.11 & 4.56 & 4 \\
\hline people & 847 & 5.4 & 5.48 & 2.81 & 6 & $\operatorname{tax}$ & 197 & 4.45 & 4.46 & 4.69 & 3 \\
\hline cousin & 51 & 5.02 & 4.78 & 2.78 & 6 & degree & 125 & 4.06 & 5.21 & 5.08 & 6 \\
\hline brother & 73 & 5.85 & 5.89 & 2.19 & 7 & professor & 57 & 5.49 & 5.87 & 5.19 & 9 \\
\hline$M$ & 206.4 & 5.05 & 5.25 & 2.67 & 5.6 & $M$ & 146.2 & 4.52 & 4.95 & 4.82 & 5.9 \\
\hline$S D$ & 251.8 & 0.87 & 0.69 & 0.21 & 2.0 & $S D$ & 80.2 & 0.97 & 0.86 & 0.27 & 2.1 \\
\hline \multicolumn{6}{|c|}{ Low Frequency, Early Acquired } & \multicolumn{6}{|c|}{ Low Frequency, Late Acquired } \\
\hline fairy & 4 & 4.33 & 5.36 & 2.42 & 5 & glare & 7 & 4.39 & 5.36 & 4.44 & 5 \\
\hline pet & 8 & 5.57 & 5.89 & 2.19 & 3 & albatross & 0 & 6.21 & 5.83 & 5.28 & 9 \\
\hline rhyme & 3 & 4.34 & 4.75 & 2.53 & 5 & ting & 0 & 3.5 & 3.16 & 4.92 & 4 \\
\hline smash & 4 & 4.02 & 5.18 & 2.78 & 5 & soprano & 6 & 4.97 & 5.35 & 5.19 & 7 \\
\hline fisherman & 5 & 5.67 & 6.1 & 2.89 & 9 & cologne & 9 & 5.76 & 5.86 & 4.94 & 7 \\
\hline berry & 9 & 5.73 & 5.51 & 2.89 & 5 & rogue & 1 & 4.24 & 4.78 & 4.44 & 5 \\
\hline rattle & 5 & 5.49 & 5.54 & 2.61 & 6 & delta & 7 & 4.94 & 4.99 & 5.54 & 5 \\
\hline peep & 2 & 3.88 & 4.37 & 2.89 & 4 & saxophone & 4 & 6.24 & 6.02 & 5.19 & 9 \\
\hline knitting & 1 & 5.83 & 5.78 & 2.86 & 8 & cue & 0 & 5.32 & 4.48 & 5.54 & 3 \\
\hline greed & 3 & 2.62 & 4.2 & 2.94 & 5 & urchin & 0 & 5.68 & 5.29 & 4.69 & 6 \\
\hline scratch & 9 & 5.23 & 5.43 & 2.69 & 7 & crypt & 1 & 5.73 & 5.53 & 5.39 & 5 \\
\hline tablespoon & 6 & 5.87 & 6 & 2.58 & 10 & crucifix & 3 & 5.64 & 5.76 & 4.75 & 8 \\
\hline hush & 4 & 3.96 & 4.67 & 2.46 & 4 & $\operatorname{disc}$ & 6 & 5.53 & 5.75 & 4.47 & 4 \\
\hline vase & 4 & 5.95 & 5.63 & 2.97 & 4 & urn & 2 & 5.51 & 5.1 & 4.42 & 3 \\
\hline satchel & 0 & 5.93 & 5.8 & 2.97 & 7 & gush & 1 & 3.96 & 4.83 & 4.53 & 4 \\
\hline elf & 0 & 4.37 & 5.43 & 2.72 & 3 & marvel & 6 & 2.93 & 4.1 & 4.89 & 6 \\
\hline$M$ & 4.2 & 4.92 & 5.35 & 2.71 & 5.6 & $M$ & 3.3 & 5.03 & 5.14 & 4.91 & 5.6 \\
\hline$S D$ & 2.8 & 1.00 & 0.57 & 0.23 & 2.1 & $S D$ & 3.1 & 0.97 & 0.75 & 0.40 & 1.9 \\
\hline
\end{tabular}

Note-KF, Kučera \& Francis (1967). Con, concreteness. Imag, imageability. AoA, age-of-acquisition ratings (Gilhooly \& Logie, 1980). L, number of letters in the word. 
APPENDIX D

Translation of English Words Used in Experiment 2

\begin{tabular}{|c|c|c|c|}
\hline High/Early & High/Late & Low/Early & Low/Late \\
\hline men* & student* & fairy & glare \\
\hline mannen & student & sprookje & blik \\
\hline step* & union & pet & albatross* \\
\hline stap & vereniging & huisdier & albatros \\
\hline breakfast & $\operatorname{sex}^{*}$ & rhyme* & ting* \\
\hline ontbijt & sexe & rijm & tingelen \\
\hline fight* & novel & smash* & soprano* \\
\hline gevecht & roman & smijten & sopraan \\
\hline page & mass & fisherman* & cologne* \\
\hline bladzijde & mis & visser & cologne \\
\hline $\operatorname{march} *$ & moral* & berry* & rogue \\
\hline mars & moreel & bes & schurk \\
\hline weather* & text* & rattle* & delta* \\
\hline weer & tekst & geratel & delta \\
\hline win* & secretary* & peep* & saxophone* \\
\hline winnen & secretaris & piepen & saxofoon \\
\hline shoulder* & science & knitting & cue \\
\hline schouder & wetenschap & breien & wenk \\
\hline find* & industry* & greed & urchin \\
\hline vinden & industrie & hebzucht & rakker \\
\hline land* & president* & scratch* & crypt* \\
\hline landen & president & kras & crypte \\
\hline newspaper & income* & tablespoon & crucifix* \\
\hline krant & inkomen & opscheplepel & crucifix \\
\hline close & rate & hush & $\operatorname{disc}^{*}$ \\
\hline dicht & snelheid & verstommen & disk \\
\hline people & $\operatorname{tax}$ & vase* & urn* \\
\hline mensen & belasting & vaas & urn \\
\hline cousin & degree* & satchel & gush \\
\hline neef & graad & schooltas & stroom \\
\hline brother* & professor* & elf** & marvel \\
\hline broer & professor & elf & wonder \\
\hline
\end{tabular}

*Cognate form.

(Manuscript received November 18, 2002;)

revision accepted for publication June 24, 2003.) 